\title{
Efektivitas Daun Belimbing Wuluh (Averrhoa bilimbi L.) Sebagai Repelent
} Alami

\section{The Effectiveness of Leaves of Starfruit (Averrhoa bilimbi L.) as Natural Repellent}

\author{
Lian varis riandi ${ }^{* 1}$, Yudha Fahrimal ${ }^{1}$, Rinidar $^{1}$, Siti Prawitasari Br. Hasibuan ${ }^{2}$, Farida \\ Athaillah $^{1}$, Sugito $^{1}$, Darmawi ${ }^{1}$ \\ ${ }^{1}$ Fakultas Kedokteran Hewan, Universitas Syiah Kuala, Banda aceh, 23111, Indonesia \\ ${ }^{2}$ Fakultas Kesehatan, Universitas Ubudiyah Indonesia, Banda aceh, 23114, Indonesia \\ *Koresponding penulis: lianvarisriandi@unsyiah.ac.id ${ }^{* 1}$, yudhafahrimal@yahoo.com ${ }^{1}$, rinidar@unsyiah.ac.id $^{1}$, \\ sitiprawitasarihasibuan@uui.ac.id², farida_athaillah_fkh@unsyiah.ac.id ${ }^{1}$, sugitofkhunsyiah@unsyiah.ac.id ${ }^{1}$, \\ darmawi@unsyiah.ac.id ${ }^{1}$,
}

\begin{abstract}
Abstrak
Indonesia merupakan salah satu negara yang beriklim tropis, sehingga sangat mendukung dalam perkembangbiakan nyamuk sepanjang tahun. Nyamuk merupakan salah satu vektor yang memiliki tingkat penyebaran penyakit yang tinggi dibanding beberapa jenis serangga lainnya, sehingga sampai saat ini masalah kejadian penyakit yang ditularkan vektor nyamuk (mosquito borne disease) masih menjadi perhatian yang utama. Upaya pengembangan insektisida alami terhadap larva nyamuk adalah salah satu solusi yang sangat baik untuk saat ini, karena bahan dasar insektisida alami merupakan tumbuhan yang bersifat toksik terhadap serangga namun tidak mencemari lingkungan, tidak meninggalkan residu di udara, air dan tanah, mudah terdegradasi serta memiliki tingkat keamanan yang lebih tinggi dibandingkan dengan racun-racun anorganik. Informasi tentang daun belimbing wuluh sebagai larvasida dengan pelarut etanol sudah ada dilaporkan, akan tetapi pengujian terhadap metode repelent yang dilarutkan dengan metanol, etil asetat dan n-hexan masih kurang.

Penelitian ini bertujuan melihat perbandingan tingkat potensi daun belimbing wuluh (Averrhoa bilimbi L.) sebagai insektisida alami yang dilarutkan dengan sifat pelarut yang berbeda. Penelitian ini merupakan penelitian eksperimental menggunakan rancangan acak lengkap dengan menggunakan metode repelent. Pengujian ini dilakukan dengan menggunakan ekstrak daun belimbing wuluh yang dilarutkan dalam tiga jenis larutan yaitu metanol, etil asetat dan n-hexan. Data pengujian repelent ditentukan dari tingkat daya proteksi nyamuk. Analisa data menggunakan anova dengan uji lanjut BNT (beda nyata terkecil).

Hasil penelitian menunjukkan bahwa ekstrak daun belimbing wuluh yang dilarutkan dengan ketiga jenis pelarut pada metode repelent memiliki pengaruh terhadap tingkat daya proteksi. Kesimpulan dari hasil penelitian ini adalah ekstrak daun belimbing wuluh berpotensi sebagai repelent, tingkat daya proteksi yang paling tinggi dilarutkan dengan pelarut metahol, etil asetat dengan tingkat daya proteksi paling rendah n-hexan.
\end{abstract}

\section{Kata kunci: Nyamuk, Repelent, Daun Belimbing Wuluh}

\author{
Abstract \\ Indonesia is a country with a tropical climate, so it is very supportive of mosquito \\ breeding throughout the year. Mosquitoes are a vector that has a high rate of disease spread
}


Journal of Healthcare Technology and Medicine Vol. 6 No. 1 April 2020

Universitas Ubudiyah Indonesia

e-ISSN : 2615-109X

compared to other types of insects, so that until now, the problem of disease incidence that is transmitted by mosquito vectors (mosquito borne disease) is still a major concern. Efforts to develop natural insecticides against mosquito larvae are a very good solution for now, because the basic ingredients of natural insecticides are plants that are toxic to insects but do not pollute the environment, do not leave residues in the air, water and soil, are easily degraded and have high levels. higher safety compared to inorganic poisons. Information about starfruit leaves as a larvicide with ethanol solvent has been reported, however, testing of the repelent method dissolved with methanol, ethyl acetate and n-hexan is still lacking.

This study aims to compare the potential levels of starfruit leaves (Averrhoa bilimbi L.) as a natural insecticide dissolved with different solvent properties. This research is an experimental study using a completely randomized design using the repelent method. This test was carried out using starfruit leaf extract dissolved in three types of solutions, namely methanol, ethyl acetate and n-hexan. Repelent test data is determined from the level of mosquito protection power. Data analysis used ANOVA with LSD further test (smallest real difference).

The results showed that the starfruit leaf extract dissolved with the three types of solvents in the repelent method had an effect on the level of protective power. The conclusion from the results of this study is that the starfruit leaf extract has the potential as a repelent, the highest level of protective power dissolved with metahol, ethyl acetate with the lowest level of protection power $n$-hexan.

\section{Key words: Mosquito, Repelent, Starfruit Leaves}

\section{Pendahuluan}

Indonesia merupakan salah satu negara yang beriklim tropis, sehingga sangat mendukung dalam perkembangbiakan nyamuk. Jumlah populasi nyamuk yang tinggi di wilayah tropis didukung oleh curah hujan yang tinggi, sehingga menyediakan tempat bagi nyamuk untuk berkembang biak. Nyamuk merupakan serangga yang sering dijumpai sekitar lingkungan kita, disamping jenis yang beragam disertai pula dengan habitat yang berbeda baik yang hidup di rawa-rawa maupun yang hidup di lingkungan perumahan (Domy, 2011).

Nyamuk merupakan salah satu vektor yang memiliki tingkat penyebaran penyakit yang tinggi diantara beberapa jenis serangga lainnya, sehingga sampai saat ini masalah kejadian penyakit yang ditularkan vektor (vector borne disease) masih menjadi perhatian yang utama. Nyamuk Culex sp., Aedes sp. serta beberapa genus lain merupakan vektor biologis yang berperan dalam penyebaran penyakit (BJEFI 2010). 
Journal of Healthcare Technology and Medicine Vol. 6 No. 1 April 2020

Universitas Ubudiyah Indonesia

e-ISSN : 2615-109X

Kebijakan bersifat preventif merupakan upaya yang sangat penting dilakukan dalam memutuskan rantai penularan penyakit yang ditularkan oleh vektor tersebut. Usaha pemberantasan vektor dilakukan dari tahap larva yaitu dengan menggunakan larvasida, hingga penggunaan insektisida untuk pembasmian nyamuk dewasa, usaha lain yang dilakukan yaitu dengan penggunaan repellent untuk mencegah dari gigitan nyamuk (Domy, 2011).

Penggunaan insektisida alami yang dilakukan oleh Domy (2011) pada nyamuk Culex sp. dewasa membuktikan bahwa air perasan buah belimbing wuluh (Averrhoa bilimbi L.) yang dilakukan dengan metode elektrik dapat berpotensi sebagai insektisida terhadap nyamuk Culex sp. dewasa. Kandungan buah belimbing wuluh (Averrhoa bilimbi L.) mempunyai zat aktif yang terdiri dari alkaloid, saponin, dan flavonoid efektif untuk membunuh larva serta nyamuk dewasa (Parikesit, 2011).

Melihat potensi daun belimbing wuluh penulis tertarik untuk meneliti daun belimbing wuluh sebagai insektisida alami yang dilarutkan dengan 3 jenis sifat pelarut yang berbeda yaitu polar (metanol), semi polar (etil asetat) dan non polar (n-hexan) untuk mengetahui pelarut yang baik untuk mengektrak daun belimbing wuluh yang digunakan sebagai insektisida alami. Perbandingan pengujian juga dilihat terhadap 3 jenis nyamuk yang berbeda yaitu Aedes aegypti, Aedes albopictus, Culex sp. .

\section{Material dan Metode}

Bahan yang digunakan dalam penelitian ini yaitu daun Belimbing wuluh, nyamuk dewasa Aedes sp. dan Culex sp. Alat yang digunakan dalam penelitian ini yaitu kandang nyamuk.

Proses Ekstrak daun belimbing wuluh

Daun belimbing wuluh yang didapat dari perkebunan masyarakat di desa Bukloh Kabupaten Aceh Besar dibawa ke Laboratorium Farmakologi Kedokteran Hewan Universitas 
Journal of Healthcare Technology and Medicine Vol. 6 No. 1 April 2020

Universitas Ubudiyah Indonesia

e-ISSN : 2615-109X

Syiah Kuala untuk dilakukan proses ektraksi. Daun belimbing wuluh yang akan diekstraksi terlebih dahulu dikering anginkan selama 24 jam, sebelum daun belimbing wuluh direndam dengan pelarut, daun tersebut dipotong-potong sehalus mungkin dan dimasukkan kedalam tabung perendaman. Perendam daun belimbing wuluh dengan pelarut dilakukan hingga daun terendam secara keseluruhan. Hasil perendaman setelah 24 jam disaring dengan menggunakan kertas saring, hasil dari penyaringan selanjutnya di masukkan kedalam rotary evaporator hingga pelarut tersebut terpisah dari komponen dan didapatkan hasil ekstraknya. Ekstrak daun belimbing wuluh yang diperoleh dimasukan kedalam botol dan disimpan kedalam refrigerator. Pengujian Repelent

Pengujian potensi ektsrak daun belimbing wuluh sebagai repelent diuji terhadap nyamuk betina dewasa yang telah dipuasakan selama 4-5 hari. Ekstrak daun belimbing wuluh diencerkan dengan menggunakan parafin cair karena penggunaan parafin cair sebagai pengenceran bersifat netral (tidak bersifat repellent/menolak ataupun attractant/memikat) terhadap nyamuk (Kardinan, 2007). Parafin cair yang tidak dicampukan dengan ekstrak daun belimbing wuluh dijadikan sebagai control negatif.

Nyamuk dewasa betina yang diuji sebanyak 25 ekor yang berada didalam kandang dengan ukuran 60x60x60 cm dngan pintu berdiameter $15 \mathrm{~cm}$. Pengujian dibutuhkan bantuan naracoba yang berpartisipasi dalam uji ini bersedia menandatangani Informed Consent dan memiliki tangan harus bersih, tidak ada bulu, tidak ada luka dan tidak memiliki riwayat alergi kulit. Tangan naracoba di beri Karet lengan (rubber sleeve) dengan memiliki lubang pada bagian lengan $5 \mathrm{~cm}$ persegi.

Tangan naracoba dioleskan ekstrak daun belimbing wuluh yang telah diencerkan dengan kosentrasi tertentu pada kedua tangan dan tangan tersebut dimasukkan kedalam kandang. Pengujian ini dimulai dari kontrol negatif dan kosentrasi paling rendah hingga paling tinggi dengan 3 kali pengulangan. 
Journal of Healthcare Technology and Medicine Vol. 6 No. 1 April 2020

Universitas Ubudiyah Indonesia

e-ISSN : 2615-109X

Perhitungan jumlah nyamuk yang hinggap pada lengan naracoba dilakukan pada tangan mulai dimasukkan kedalam kandang selama 10 menit, pada tiap interval waktu mulai jam ke 1 , 2, 3. Perhitungan daya proteksi daun belimbing wuluh dilakukan dengan menggunakan rumus dengan menggunakan rumus ( Xue, et al., 2001) :

Daya Proteksi $=$

\section{$\sum$ nyamuk hinggap pada kontrol - $\sum$ pada perlakuan}

\section{Analisis data penelitian}

Data dianalisis dengan analisis varian (ANAVA), jika hasil menunjukkan pengaruh yang nyata $(\mathrm{P}<0,05)$ maka dilanjutkan dengan uji BNT (Beda Nyata Terkecil). Setiap pengujian dilakukan Analisis Probit dengan program SPSS ver18.

\section{Hasil dan Pembahasan}

Pengujian repelent dilakukan pada nyamuk dewasa betina yang telah dipuasakan selama 4-5 hari, pengujian ini disesuaikan dengan kondisi waktu nyamuk aktif menghisap darah. Nyamuk Aedes aegypti dewasa memiliki kebiasaan menghisap darah pada jam 08.00-12.00 WIB dan sore hari 15.00-17.00 WIB dan nyamuk Aedes albopictus lebih aktif pada siang hari (Soegijanto, 2006). Nyamuk Culex sp. dewasa memiliki kebiasaan menghisap darah pada pukul 22.00-02.00 WIB (Hadi dan Koesharto, 2006).

Hasil rata-rata pengujian ekstrak daun belimbing wuluh (Averrhoa bilimbi L.) dengan metode repelent (ditampilkan pada tabel 1) memiliki hasil yang bervariatif diantara setiap pelarut. Hasil tersebut menunjukkan bahwa setiap pelarut memiliki tingkat kemampuan masing-masing pada daya hinggap nyamuk. Daya hinggap nyamuk pada setiap ektrak dengan pelarut tertentu, memiliki tingkat daya hambat yang berbeda, dapat dilihat pada tabel berikut. 
Journal of Healthcare Technology and Medicine Vol. 6 No. 1 April 2020

Universitas Ubudiyah Indonesia

e-ISSN : 2615-109X

Tabel 1. Rata-rata jumlah nyamuk yang hinggap (ekor)

a. Nyamuk Aedes aegypti

\begin{tabular}{lcccc}
\hline \multirow{2}{*}{ Pelarut } & $\mathbf{0}$ & $\mathbf{2 5}$ & $\mathbf{5 0}$ & $\mathbf{1 0 0}$ \\
\cline { 2 - 5 } N-Heksan & 104 & $92,33 \pm 5,39$ & $93,33 \pm 5,39$ & $94,33 \pm 5,39$ \\
\hline Methanol & 104 & $57,67 \pm$ & $41,00 \pm 35,16$ & $21,67 \pm 35,16$ \\
& & 35,16 & & \\
\hline Etil Asetat & 104 & $95,33 \pm$ & $87,00 \pm 15,07$ & $68,67 \pm 15,07$ \\
& & 15,07 & & \\
\hline Jumlah & $\mathbf{3 1 2}$ & $\mathbf{2 4 5 , 3 3}$ & $\mathbf{2 2 1 , 3 3}$ & $\mathbf{1 8 4 , 6 7}$ \\
\hline
\end{tabular}

b. Nyamuk Aedes albopictus

\begin{tabular}{|c|c|c|c|c|}
\hline \multirow[b]{2}{*}{ Pelarut } & \multicolumn{4}{|c|}{ Dosis } \\
\hline & $\mathbf{0}$ & 25 & 50 & 100 \\
\hline N-Heksan & 108 & $99 \pm 14,55$ & $92 \pm 14,55$ & $73,67 \pm 14,55$ \\
\hline Methanol & 108 & $55,33 \pm 36,82$ & $46 \pm 36,82$ & $20,33 \pm 36,82$ \\
\hline Etil Asetat & 108 & $95,33 \pm 19,89$ & $81 \pm 19,89$ & $61,67 \pm 19,89$ \\
\hline Jumlah & 324 & 249,66 & 219 & 155,67 \\
\hline \multicolumn{5}{|l|}{ c. Nyamuk Culek } \\
\hline & \multicolumn{4}{|c|}{ Dosis } \\
\hline Pelarut & $\mathbf{0}$ & 25 & 50 & 100 \\
\hline N-Heksan & 82 & $44 \pm 21,56$ & $\begin{array}{c}41,67 \pm \\
21,56\end{array}$ & $33,67 \pm 21,56$ \\
\hline Methanol & 82 & $24 \pm 33,26$ & $\begin{array}{c}17,33 \pm \\
33,26\end{array}$ & $8,67 \pm 33,26$ \\
\hline Etil Asetat & 82 & $43,67 \pm 23,09$ & $35 \pm 23,09$ & $32 \pm 23,09$ \\
\hline Jumlah & 246 & 111,67 & 94 & 74,34 \\
\hline
\end{tabular}

Hasil rata-rata jumlah nyamuk yang hinggap bila dilihat dari jenis nyamuk menunjukkan nyamuk Culek memiliki daya hinggap yang lebih rendah dibandingkan dengan nyamuk Aedes Albopictus dan Aedes aegypti. Perbandingan daya hinggap nyamuk dilihat dari ekstrak yang dilarutkan pada ketiga jenis pelarut, menunjukkan bahwa hasil rata-rata jumlah nyamuk yang hinggap pada ekstrak dengan pelarut methanol lebih sedikit bila dibandingkan 
Journal of Healthcare Technology and Medicine Vol. 6 No. 1 April 2020

Universitas Ubudiyah Indonesia

e-ISSN : 2615-109X

dengan pelarut etil asetat dan N-heksan.

Hasil peneitian ini menunjukkan bahwa ekstrak daun belimbing wuluh (Averrhoa bilimbi L.) yang dilarutkan dengan ketiga jenis pelarut tersebut memiliki aktifitas repelent terhadap nyamuk betina Aedes aegypti, Aedes albopictus dan Culex dalam kondisi laboratorium. Hasil identifitaksi menunjukkan bahwa hasil ekstrak daun belimbing wuluh ((Averrhoa bilimbi L.) mengandung senyawa aktif golongan terpenoid yang berperan sebagai repelent. Kandungan terpenoid berperan aktif pada uji repelent, pengujian pada nyamuk Aedes aegypti betina dengan menggunakan ektrak kulit jeruk nipis dalam sediaan lotion dengan kosentrasi 55\% mengandung senyawa golongan terpenoid dapat menolak nyamuk selama 36 menit 1 detik (Tesaviani, 2009). Penelitian Choi, dkk. (2002) kandungan terpenoid yang terdapat pada minyak atsiri Thymus vulgaris pada kosentrasi 0,05\% dan penelitian Jebanesan dan Rajkumar (2005), minyak atsiri dari tanaman Moschosma polystachyum pada konsentrasi 4\% mengandung terpenoid yang dapat menghasilkan aktivitas repelent.

Untuk melihat hasil pengaruh nyata pada setiap pelarut maka dilanjutkan dengan uji BNT (Beda Nyata Terkecil). Hasil uji BNT terhadap jenis pelarut menunjukkan bahwa daya hinggap nyamuk pada pelarut metanol berbeda secara nyata $(\mathrm{P}<0,05)$ bila dibandingkan dengan pelarut etil asetat dan $n$-hexan, sedangkan pelarut etil asetat tidak berbeda secara nyata $(P>0,05)$ dibandingkan dengan pelarut n-hexan. Hasil ini membuktikan bahwa pelarut metanol ekstrak daun belimbing wuluh (Averrhoa bilimbi L.) pada semua kelompok konsentrasi mempunyai daya hambat yang lebih baik dibandingkan dengan pelarut n-heksan dan etil asetat.

Jumlah nyamuk yang hinggap pada setiap pengujian mempunyai pengaruh dari pelarut ekstraksi yang digunakan. Hal ini membuktikan penggunaan pelarut metanol diasumsikan bahwa zat toksik yang terdapat pada senyawa non polar dan polar serta berperan dalam daya 
Journal of Healthcare Technology and Medicine Vol. 6 No. 1 April 2020

Universitas Ubudiyah Indonesia

e-ISSN : 2615-109X

repelent terlarut secara sempurna pada saat proses ekstraksi (Sihombing, 2015). Renanggalih

et al., (2014), menyatakan bahwa kandungan flavonoid, saponi dan tanin pada daun belimbing wuluh (Averrhoa bilimbi L.) dapat berperan sebagai repelent nyamuk.

Hasil uji BNT pada tingkat dosis menunjukkan bahwa terdapat perbedaan yang nyata $(\mathrm{P}<0,05)$ diantara kelompok konsentrasi 0, 25\%, 50\% dan 100\% (Tabel 2). Daya hinggap nyamuk yang paling rendah terdapat pada kosentrasi $100 \%$, kemudian diikuti dengan konsentrasi 50\%, $25 \%$ dan 0\%. Hasil ini membuktikan bahwa konsentrasi $100 \%$ ekstrak daun belimbing wuluh (Averrhoa bilimbi L.) pada semua kelompok pelarut mempunyai daya hambat yang lebih baik dibandingkan dengan konsentrasi 50\%, 25\% dan 0\%.

Tingkatan dosis pada pengujian repelent berpengaruh terhadap daya hinggap nyamuk. Kemampuan repelent merupakan suatu senyawa yang bereaksi secara lokal atau pada jarak tertentu memiliki kemampuan terhadap daya hambat antropoda untuk mendarat atau menggigit pada permukaan kulit manusia atau hewan (Nerio, et al., 2010). Dengan demikian hasil penelitian ini sejalan dengan penelitian yang telah dilakukan oleh Djadmiko, et al., (2004), menyatakan pada kosentrasi $40 \%$ memiliki daya repelent lebih tinggi bila dibandingkan dengan kosentrasi $20 \%$ dan $10 \%$.

Hasil uji BNT terhadap jenis nyamuk menunjukkan bahwa daya hinggap pada nyamuk Culex sp. berbedaan secara nyata $(\mathrm{P}<0,05)$ dibandingkan dengan nyamuk Aedes aegypti dan Aedes albopictus, namun daya hinggap nyamuk Aedes aegypti tidak berbeda secara nyata ( $\mathrm{P}>0,05)$ dibandingkan dengan Aedes albopictus (lampiran 6).

Untuk melihat tingkat daya proteksi ekstrak daun belimbing wuluh (Averrhoa bilimbi L.) yang dilarutkan dengan masing-masing dapat dilihat pada tabel 4.

Tabel 3. Daya Proteksi uji repelent terhadap daya hinggap nyamuk Aedes aegypti, Aedes albopictus dan Culek sp. setelah pemberian ekstrak daun belimbing wuluh dalam berbagai pelarut. 


\begin{tabular}{|c|c|c|c|c|c|c|c|c|c|c|}
\hline \multirow{3}{*}{ Pelarut } & \multirow{3}{*}{$\begin{array}{c}\text { DOSIS } \\
(\%)\end{array}$} & \multicolumn{9}{|c|}{ Jenis Nyamuk dan waktu pengamatan perjam } \\
\hline & & \multicolumn{3}{|c|}{ Aedes Aegypti } & \multicolumn{3}{|c|}{ Aedes Albopictus } & \multicolumn{3}{|c|}{ Culex sp } \\
\hline & & 1 & 2 & 3 & 1 & 2 & 3 & 1 & 2 & 3 \\
\hline \multirow{3}{*}{ Metanol } & 25 & 40,95 & 41,90 & 45,08 & 49,69 & 47,53 & 48,77 & 67,89 & 69,51 & 70,73 \\
\hline & 50 & 57,46 & 56,51 & 58,10 & 58,95 & 56,79 & 57,41 & 76,83 & 78,05 & 78,86 \\
\hline & 100 & 79,37 & 80,32 & 79,37 & 81,48 & 80,86 & 81,17 & 89,84 & 90,24 & 89,43 \\
\hline \multirow{3}{*}{$\begin{array}{c}\text { Etil } \\
\text { asetat }\end{array}$} & 25 & 12,06 & 11,11 & 10,16 & 11,73 & 14,20 & 11,73 & 47,15 & 47,56 & 46,75 \\
\hline & 50 & 24,76 & 17,46 & 17,14 & 22,53 & 28,09 & 25,00 & 55,28 & 58,13 & 57,32 \\
\hline & 100 & 38,10 & 42,86 & 34,60 & 44,14 & 48,77 & 42,90 & 62,20 & 64,63 & 60,98 \\
\hline \multirow{3}{*}{$\begin{array}{c}\mathrm{N}- \\
\text { hexan }\end{array}$} & 25 & 2,54 & 8,57 & 6,35 & 11,11 & 9,26 & 8,33 & 46,75 & 44,72 & 46,34 \\
\hline & 50 & 15,56 & 11,75 & 9,52 & 22,22 & 15,43 & 14,81 & 48,37 & 50,00 & 49,19 \\
\hline & 100 & 26,98 & 29,21 & 25,71 & 28,70 & 26,85 & 31,79 & 57,32 & 58,54 & 58,94 \\
\hline
\end{tabular}

Pada tabel 4 terlihat menunjukkan bahwa daya proteksi nyamuk pada pengujian repelent berbanding terbalik dengan jumlah hinggap nyamuk. Semakin tinggi daya proteksi yang di dapatkan semakin rendah daya hinggap nyamuk yang diperoleh. Pada ekstrak daun belimbing wuluh (Averrhoa bilimbi L.) dengan menggunakan pelarut metanol daya proteksi lebih tinggi dibandingkan dengan pelarut etil asetat dan n-hexan pada semua kosentrasi. Daya proteksi yang paling rendah terlihat pada pelarut n-hexan pada jenis nyamuk Aedes aegypti pada semua kosentrasi.

Pada penelitian ini juga memperlihatkan bahwa pada uji repelent semakin tinggi kosentrasi yang digunakan pada berbagai pelarut semakin tinggi daya proteksinya. Hal yang mengembirakan bahwa dalam waktu 3 jam pengamatan ke-3 ekstrak dengan pelarut yang berbeda masih mampu bekerja sebagai repelent dan berbanding lurus dengan daya proteksi.

\section{Kesimpulan}

Berdasarkan hasil penelitian dapat disimpulkan bahwa ekstrak daun belimbing wuluh yang dilarutkan dengan pelarut metanol, etil asetat dan n-hexan dapat berfungsi sebagai repelent, dan pelarut yang paling baik adalah metanol, Semakin tinggi dosis yang digunakan pada pengujian repelent semakin besar daya proteksi. 


\section{Referensi}

[BJEFI] Buletin Jendela Epidemiologi Filariasis di Indonesia. (2010). Pusat Data dan Surveilans Epidemiologi Kementrian Kesehatan RI. Volume.1

Choi, W.S., Park B.S., Ku S.K., Lee S.E. 2002. Repellent activities of essential oils and monoterpenes againts Culex pipiens pallens, J. Am. Msog. Control. Assoc. 18 (4): 348351.

Hadi, U.K., dan F. Koesharto. 2006. Nyamuk. di dalam : Sigit S.H, Hadi UK, editor. Hama Pemukiman Indonesia Pengenalan, Biologi, dan Pengendalian. IPB, Bogor. Hal 23-51.

Jebanesan, A. and Rajkumar, S., 2005, Repellency of volatile oils from Moschosma polystachyum and Solanum xanthocarpum againts filarial vector Culex quinquefasciatus Say, Trop. Biomed. 22 (2) : 139-142.

Kardinan, A. 2001. Pestisida Nabati Ramuan dan Aplikasi. Penebar Swadaya, Jakarta.

Parikesit, Mario. 2011. Khasiat dan manfaat belimbing wuluh. Stomata, Surabaya. Hal 1-13; 67-104.

Renaninggalih, R. 2014. Karakterisasi dan pengujian aktivitas penolak nyamuk minyak atsiri daun kecombrang (etlingera elatior (jack) r. M. Smith). Program Studi Farmasi, FMIPA UNISBA. Bandung.

Sihombing, M., Y. Afiffuddin. dan L. Hakim. 2015. Bahan Anti Nyamuk (Mosquito repellent) dari Akar Tuba (Derris elliptica (Roxb.) Benth) (Material Mosquito Repellent of Tuba Root (Derris elliptica (Roxb.) Benth) Fakultas Pertanian Universitas Sumatera Utara, Medan.

Soegijanto, S. 2006. Demam Berdarah Dengue. Edisi kedua. Airlangga University Press. Surabaya.

Tesaviani, K., 2009, Daya Repelan Ekstrak Kulit Buah Jeruk Nipis (Citrus aurantifolia Swingle) dalam Sediaan Lotion Terhdap Nyamuk Aedes aegypti, Skripsi, Fakultas Kedokteran UGM, Yogyakarta. 